\title{
Realismo Nominal no Processo de Alfabetização de Crianças e Adultos
}

\author{
Nominal Realism on Children and Adults Literacy Process
}

\author{
Alena Nobre* \& Antonio Roazzi \\ Universidade Federal de Pernambuco, Recife, Brasil
}

\begin{abstract}
Resumo
Este estudo teve como objetivo avaliar a influência do realismo nominal nas atividades de leitura, escrita e matemática. Foram examinadas 39 crianças da primeira, segunda e quarta séries e 15 adultos da primeira etapa do primeiro ciclo da Educação de Jovens e Adultos. A amostra foi submetida a atividades de realismo nominal, matemática e leitura e escrita de palavras e pseudopalavras. Os dados indicaram que o realismo nominal está relacionado significativamente com as variáveis leitura, escrita e matemática. Tais resultados reafirmam a interferência do realismo nominal no desempenho em leitura e escrita, e sugerem a correlação do mesmo nas atividades matemáticas.

Palavras-chave: Realismo nominal; Matemática; Leitura; Escrita.
\end{abstract}

\begin{abstract}
The aim of this study was to evaluate the relation among nominal realism and reading, writing as well as mathematics activities. Participants were thirty-nine children of the first, second and fourth grades and fifteen adults at the first stage of the first cycle of adult and young education. The tasks used were reading, spelling words and pseudo-words, nominal realism and mathematics. Results indicate that nominal realism is significantly related to reading, writing and mathematics. These findings reaffirm the interference of nominal realism in reading and spelling activities, and indicate also a strong correlation with mathematical abilities.

Keywords: Nominal realism; Mathematics; Reading; Writing.
\end{abstract}

O realismo nominal é uma característica do pensamento infantil em função do qual a criança expressa dificuldades em dissociar o signo da coisa significada (Piaget, 1962). O sujeito que, em determinado momento do desenvolvimento cognitivo, apresenta este pensamento realista nominal, tende a conceber a palavra como parte integrante do objeto, atribuindo ao signo características do objeto ao qual se refere. Piaget (1962) conceituou dois tipos de realismo nominal: o ontológico e o lógico.

O realismo nominal ontológico consiste na confusão da existência, origem e localização das palavras com os objetos a que elas se referem. Questionando crianças entre 5 a 6 anos sobre esses aspectos, Piaget (1962) percebeu que elas acreditavam que os nomes emanavam das coisas e que se localizavam, de forma invisível, no próprio objeto. Algumas crianças, por exemplo, afirmavam ser necessário apenas olhar para o sol para saber que ele se chamava 'sol'.

Já o realismo nominal lógico caracteriza-se pela atribuição de um valor lógico intrínseco à palavra. Uma das

\footnotetext{
* Endereço para correspondência: Universidade Federal de Pernambuco, Centro de Ciências Humanas, Rua Acadêmico Hélio Ramos, s/n, Cidade Universitária, Recife, PE, Brasil, CEP 50670-901. E-mails: alenacabral@yahoo.com.br e roazzi@gmail.com
}

perguntas sugeridas por Piaget (1962) para avaliar este tipo de realismo nominal era a seguinte: "Poderíamos chamar o 'sol' de 'lua' e a 'lua' de 'sol'?". As crianças que se encontravam nesse nível afirmavam não ser possível chamar o 'sol' de 'lua' porque o sol é grande e brilhante e não poderia diminuir para ficar do tamanho da lua. Assim, Piaget (1962) concluiu que nessa fase, as crianças conferem ao nome características do objeto de tal forma que, para elas, se o nome muda, alteram-se também as particularidades do objeto.

O realismo nominal foi citado por diversos autores como um conceito importante na teoria de Piaget, e muitos pesquisadores realizaram investigações cujos resultados confirmaram as observações piagetianas (Ball \& Simpson, 1977; Church, 1961; Furth, 1969; Gerschitz \& Glick, 1981; Markman, 1976; Papandropoulou \& Sinclair, 1974; Pulaski, 1971; Werner, 1948; Williams, 1990, entre outros).

No Brasil, os estudos realizados por Carraher e Rego (1981, 1984) marcaram um importante momento nas produções científicas sobre o realismo nominal. Essas pesquisas indicaram que as crianças que apresentavam realismo nominal lógico obtinham baixo desempenho nas atividades de leitura e análise fonêmica. A correlação entre escrita e realismo nominal não apresentava coeficientes significantes em todas as ocasiões, mas, de modo geral, a 
aprendizagem da leitura e escrita mostrava-se mais efetiva em crianças que já haviam superado o realismo nominal lógico. Estudos posteriores ratificaram a correlação positiva entre realismo nominal, leitura, escrita, consciência metalinguística e consciência fonológica (Andreazza-Balestrin, Cielo, \& Lazarotto, 2008; Aquino, 2007; Bezerra, 1981; Maluf \& Barrera, 1997; Monteiro, 1981).

Atualmente, a concepção do realismo nominal já é reconhecida e incorporada aos estudos que fazem referencia à alfabetização e à consciência fonológica (Gindri, Keske-Soares, \& Mota, 2007; Maia \& Fonseca, 2002; Miranda, 2008; Roazzi \& Carvalho, 1995; Simões, 2000). Além disso, os resultados dessas investigações contribuíram para a prática dos psicólogos e psicopedagogos que, hoje, utilizam os testes de realismo nominal como medida de consciência fonológica e suporte ao diagnóstico de dificuldades na leitura e escrita (Salvari, 2004).

Apesar de toda a contribuição das pesquisas, poucas vezes o realismo nominal é o objeto principal de estudo. Sendo assim, ainda existem aspectos que precisam ser mais explorados. As investigações nesta área são, em geral, realizadas com amostras de crianças, o que pode limitar a compreensão do fenômeno. Alguns estudos foram realizados com adultos, no entanto, foram pouco discutidos na literatura.

Monteiro (1981), por exemplo, realizou um estudo sobre a correlação entre habilidades metalinguísticas e realismo nominal em adultos analfabetos. O pesquisador encontrou um alto índice de respostas do nível intermediário do realismo nominal, ou seja, que caracterizavam que o sujeito estava próximo a superá-lo. Entretanto, ele explicou que tais resultados poderiam estar mais correlacionados às dificuldades de verbalização das justificativas na tarefa do que aos conflitos relacionados à natureza do realismo nominal.

Melo (2004) realizou um estudo sobre a relação entre letramento e realismo nominal. A pesquisadora supunha que um sujeito inserido culturalmente e já habituado a utilizar-se funcionalmente da leitura, ainda que não dominasse o código escrito, superaria mais facilmente o realismo nominal. Entretanto, os resultados apontaram que o maior grau de letramento ${ }^{1}$ não era um elemento importante à superação do realismo nominal.

\footnotetext{
${ }^{1}$ De acordo com Soares (2004) embora a relação entre alfabetização e letramento seja inegável, é preciso levar em consideração as diferenças e especificidades de cada um destes fenômenos. Enquanto a alfabetização envolve processos relativos à aquisição do sistema convencional de escrita, o letramento compreende o desenvolvimento de habilidades de uso desse sistema em atividades de leitura e escrita e nas práticas sociais que envolvem a língua escrita. Diante desta diferenciação, é possível compreender que o realismo nominal está mais associado à alfabetização do que ao letramento pela correlação do mesmo com o desenvolvimento da consciência fonológica; aspecto elementar para alfabetização, mas não para o letramento.
}

Camargo (2007) realizou uma pesquisa com o objetivo de levantar dados sobre a importância da rima na alfabetização de adultos. A pesquisadora avaliou o realismo nominal como obstáculo à aprendizagem da leitura, embora não fosse esse o objetivo principal do estudo. Os resultados, avaliados a partir de dois estudos de caso, confirmaram a presença do realismo nominal em adultos. No entanto, foi mais discutido como os adultos justificavam suas respostas a partir das suas relações com o mundo do que propriamente com as questões relacionadas ao realismo nominal na Educação de Jovens e Adultos (EJA).

Como visto, estudos anteriores mencionam a presença do realismo nominal em adultos analfabetos, porém, não há evidência de estudos comparativos entre crianças e adultos. Comparar o desempenho nas tarefas de realismo nominal e consciência metalinguística em adultos e crianças pode nos trazer mais contribuições sobre as dificuldades inerentes à compreensão do sistema notacional alfabético e às, exclusivamente, relacionadas ao pensamento infantil.

Outra lacuna percebida nos estudos de realismo nominal é que há uma tendência em relacioná-lo apenas às variáveis de leitura, escrita e consciência fonológica. Todavia, diante da natureza do fenômeno estudado (a dificuldade em perceber relações simbólicas arbitrárias e desligar-se da percepção do concreto), é preciso questionar se outras atividades simbólicas, como as atividades matemáticas, por exemplo, também sofrem influência do pensamento realista nominal.

Assim, o objetivo deste artigo foi reavaliar e ampliar as investigações sobre realismo nominal, levando em consideração o desempenho nas atividades de realismo nominal, leitura, escrita e matemática nas amostras de crianças e adultos. A hipótese que fundamentou esta investigação é a de que tanto crianças quanto adultos apresentam realismo nominal em níveis de desenvolvimento diferentes, e que tal fenômeno afeta a aquisição do sistema notacional alfabético e numérico. Outra hipótese desta investigação é a probabilidade de se encontrar predição entre as variáveis do estudo.

Como visto no exame da literatura, não foram encontradas pesquisas anteriores que investigaram a correlação entre matemática e realismo nominal, nem estudos comparativos entre amostras de diferentes idades. A possibilidade de compreender a influência do realismo nominal sobre outras atividades simbólicas, bem como a de discutir mais profundamente aspectos diferenciais deste fenômeno em adultos e crianças, pode ajudar a compreender melhor as dificuldades características ao processo evolutivo da aquisição dos sistemas notacionais. Diante disso, tornar-se-ia mais fácil direcionar ações pedagógicas visando facilitar a apropriação do código escrito por crianças e adultos. 


\section{Método}

\section{Participantes}

A pesquisa foi realizada em uma escola estadual da região metropolitana de Recife/PE que oferece as séries iniciais do Ensino Fundamental regular e Educação de Jovens e Adultos. Participaram 54 sujeitos, divididos em dois grupos: crianças e adultos. $\mathrm{O}$ grupo de crianças era composto por: 12 sujeitos do primeiro ciclo do primeiro ano ( $1^{\mathrm{a}}$ série), 15 sujeitos do segundo ciclo do primeiro ano ( $2^{\mathrm{a}}$ série); 12 sujeitos do segundo ciclo do segundo ano ( $4^{\mathrm{a}}$ série). $\mathrm{O}$ outro grupo foi composto por 15 jovens e adultos do primeiro ano, o que corresponde a $1^{\mathrm{a}}$ e $2^{\mathrm{a}}$ séries do Ensino Fundamental.

Participaram da amostra apenas os alunos que estavam dentro da faixa etária correspondente às séries em curso, ou seja, que nunca haviam repetido o ano. Em relação aos adultos, um critério adicional foi utilizado: só participaram aqueles que estavam cursando pela primeira vez o primeiro ano da EJA. Além disso, sujeitos que apresentaram resultados abaixo da média do grupo no sub-teste de vocabulário do WISC, foram excluídos da amostra da pesquisa a fim de evitar erros na análise estatística.

Os sujeitos participaram em caráter voluntário, após autorização dos pais (quando necessário), diretores e professores da escola, seguindo as diretrizes éticas que regem a pesquisa com seres humanos.

\section{Procedimentos e Instrumentos}

A coleta de dados durou quatro meses. Foi realizada em uma sala da escola, onde permaneciam apenas a pesquisadora e um(a) aluno(a). A ordem na aplicação das tarefas foi determinada de forma aleatória, por meio de sorteio. Nenhuma das tarefas exigia limite de tempo para realização. Os alunos dispuseram do tempo necessário para completar as tarefas propostas.

Segue abaixo a descrição das tarefas utilizadas:

Sub-testes do WISC. Foram apresentadas oralmente quarenta palavras em ordem crescente de dificuldade. Os sujeitos eram incentivados a explicar o significado da palavra que havia sido dita. Na avaliação, levou-se em consideração não a linguagem usada pelo aluno, mas a aceitabilidade do sentido dado à palavra. Além deste subteste de vocabulário, foram aplicados também os sub-testes de ordem direta e ordem inversa.

Avaliação do Realismo Nominal. Esta atividade visou avaliar se o sujeito entrevistado apresentava indícios de realismo nominal. Foram realizadas duas tarefas distintas, ambas aplicadas por meio do método clínico piagetiano. A primeira tarefa de realismo nominal tomou como referência perguntas utilizadas nos protocolos de Carraher e Rego (1981, 1984) e Piaget (1962). Seguem exemplos de algumas perguntas feitas aos participantes: (a) "O seu nome é... Como é o nome do seu irmão? Você pode ser chamado de [nome do irmão] e o seu irmão de [nome do adulto]?"; (b) "Qual é a maior palavra, boi ou formiga? Por quê?"; (c) "Me diga uma palavra pare- cida com a palavra bola"; (d) "Que tipo de som emitiria um gato se por acaso fosse chamado de cachorro? Por quê?"”.

A segunda tarefa foi baseada no estudo de Carraher e Rego (1981) e de Monteiro (1981), que consistia em perguntar ao sujeito sobre o tamanho das palavras. Essa tarefa visava não só avaliar o realismo nominal lógico, mas também a consciência metalinguística do entrevistado. A pesquisadora dizia ao entrevistado duas palavras (Ex.: boi/muriçoca; biscoito/pão; tijolinho/casa; anãozinho/gigante) e perguntava qual delas era a maior. O participante era estimulado a justificar sua resposta.

Nesta segunda tarefa de realismo nominal, as respostas serviram não só para a categorização em níveis, mas também para medir a consciência metalinguística dos sujeitos. Para isso, foi contabilizado o número de respostas corretas dadas pelos participantes nos itens de palavras reais. A justificativa em utilizar um teste de realismo nominal como medida de consciência metalinguística é a mesma proposta e utilizada por Bezerra (1981): a resposta na tarefa do realismo nominal exige do sujeito o tratamento da palavra como objeto lingüístico, o forçando a voltar a atenção sobre a própria língua.

Em ambas as tarefas de realismo nominal, as respostas e justificativas dos sujeitos foram gravadas e, a seguir, transcritas. Após a transcrição da tarefa pela pesquisadora, dois juízes avaliaram o nível do realismo nominal, de forma independente, por meio das três categorias usadas por Carraher e Rego (1981).

As categorias utilizadas foram as seguintes: NÍVEL 1A - Foram classificadas neste nível as respostas baseadas principalmente no significado. Os sujeitos respondiam que as palavras grandes eram nomes de coisas grandes e palavras pequenas eram nomes de coisas pequenas. Embora surgissem referências a letras e sons, os participantes se expressavam, na maioria das vezes, de forma incoerente, sem saber justificar as respostas. NÍVEL 1B - Neste nível era possível perceber a transição entre o nível $1 \mathrm{~A}$ para o nível 2. As respostas demonstravam que os participantes tinham alguma consciência da palavra, mas ainda deixavam-se influenciar pela ideia que a palavra representava em várias ocasiões, principalmente nos itens mais sugestivos, tais como anãozinho e gigante. Após a aplicação das duas tarefas, os resultados foram comparados. Quando ocorriam categorizações opostas nas tarefas, era sugerida a possibilidade de o sujeito encontrar-se na fase de transição; NÍVEL 2 - As respostas correspondentes a este nível demonstravam que os sujeitos eram capazes de focalizar a palavra, independentemente do seu significado. Embora pudessem, ocasionalmente, apresentar uma resposta isolada baseada no significado, as respostas semânticas não constituíam a base de sua abordagem à tarefa e, em geral, não aconteciam nos itens mais sugestivos.

Tarefa de Leitura de Palavras e Pseudopalavras. Foram apresentadas aos alunos, individualmente, duas listas de palavras (ex.: pano, tecido, laranjada, marinheiro) 
e pseudopalavras (ex.: laco, potefó, gamitária), de forma randomizada. Ao todo, foram utilizadas 25 palavras conhecidas e outras 25 palavras inventadas. As palavras foram selecionadas do estudo de Lima (2002), tendo como critério de escolha a dificuldade crescente representada por meio da estrutura silábica (consoante-vogal) e da tonicidade.

As palavras foram apresentadas em cartões de $4 \mathrm{~cm} \mathrm{x}$ $12 \mathrm{~cm}$, em fonte arial, caixa alta, tamanho 48 . Foi registrado o tempo de duração e gravado todo o áudio da entrevista para posterior transcrição fonética.

Esta tarefa foi avaliada de duas formas: a primeira analisou o nível de leitura no qual o sujeito se encontrava; a segunda contou o número de acertos na leitura de palavras levando em consideração, apenas, o quesito decodificação.

A fim de analisar os níveis de leitura de palavras, foram elaboradas para este estudo categorias embasadas na classificação sugerida por Moreira (2006), sendo estas: NÍVEL 1 - Sujeito não lê de forma convencional, não sendo capaz de compreender ou processar palavras inteiras. Reconhece algumas letras, mas não compreende o sentido da palavra. Em muitas ocasiões, os sujeitos tentavam decodificar a palavra através de adivinhações linguísticas; NÍVEL 2 - Lê segmentando. Por meio de decifração fonológica, os sujeitos processavam as palavras de estrutura simples, como as paroxítonas formadas por duas ou três sílabas no padrão consoante-vogal (CV), exemplo: 'bela' e 'caneco'; NÍVEL 3 - Lê palavras estruturalmente simples com fluência; NÍVEL 4 - Lê palavras de estruturas simples e complexas com fluência.

Tarefa de Escrita de Palavras e Pseudopalavras. Esta tarefa, assim como a anterior, tinha como objetivo controlar possíveis influências das variáveis realismo nominal e consciência metalinguística, bem como avaliar os estágios da escrita como proposto por Ferreiro e Teberosky (1991): hipótese pré-silábica, silábica, silábico-alfabética e alfabética.

A atividade foi dividida em dois momentos nos quais constavam o ditado de palavras (ex.: pé, maçã, escravo, tornozelo) e pseudopalavras (ex.: vico, darilho, zatabelo) que deveriam ser escritas pelos alunos. Foi dado o intervalo de uma semana para a realização do ditado seguinte. As palavras, transcritas do estudo de Lima (2002), foram selecionadas a partir de uma ordem de dificuldade crescente relativa à estrutura e divisão silábica.

Tarefa de Matemática. Foi utilizada a tarefa aplicada no estudo de Nunes e Moreno (1998) com o objetivo de avaliar o raciocínio lógico e aritmético dos participantes. A atividade era composta por 30 questões. Em todas elas era oferecido suporte visual, tais como desenhos, ou dicas de resolução. Segue abaixo exemplo de uma das questões: "Temos 36 pirulitos para distribuir entre 3 crianças. Todas querem ganhar a mesma quantidade. Quantos pirulitos cada uma vai ganhar? Escreva sua resposta no quadrinho."
A atividade foi aplicada coletivamente. A pesquisadora lia a tarefa em voz alta e perguntava se a turma havia compreendido o objetivo da questão, a fim de evitar a interferência da má compreensão da leitura e garantir que todos os alunos soubessem o que era proposto.

Além das tarefas detalhadamente descritas acima, foram aplicadas também tarefas de categorização de sons, subtração de fonemas, identificação e produção de rima. A descrição destas tarefas podem ser encontradas no estudo de Lima (2002).

\section{Resultados}

A princípio, os dados foram analisados estatisticamente a partir de testes de correlação e de análise de correspondência múltipla - HOMALS. Este teste é um procedimento estatístico de redução de dados, cujo objetivo é analisar a relação de homogeneidade entre variáveis nominais em duas ou três dimensões. Através dos gráficos produzidos, torna-se possível perceber o quanto as variáveis se aproximam ou se distanciam umas das outras. A escolha deste procedimento de análise decorre da própria natureza dos dados que envolve categorias múltiplas. É possível analisar as virtuais correspondências entre estas categorias, estando em presença de mais que duas ou mais variáveis com um número de níveis, por vezes, diferente, ou mesmo diferentes níveis de medida. É assim uma estatística de redução dos dados, pela análise de correspondência múltipla, com uma série de variáveis, todas nominais múltiplas. Enfim, o procedimento HOMALS analisa a relação de homogeneidade entre as variáveis (das colunas e das linhas) em duas dimensões, produzindo projeções correspondentes, sendo o mais importante a projeção das quantificações das categorias (para maiores detalhes ver De Leeuw \& Van Rijckevorsel, 1980; Guttman, 1941; Tenenhaus \& Young, 1985).

Na Figura 1, por exemplo, pode-se observar a proximidade entre a série e o nível de realismo nominal. Ao traçar uma linha imaginária ao meio da figura, no sentido vertical, percebe-se que o lado direito mostra a relação próxima entre os níveis mais baixos do realismo nominal (1A e 1B) com a $1^{\mathrm{a}}$ série e EJA. O lado esquerdo da figura indica justamente o contrário; ou seja, a maioria das crianças da $2^{\mathrm{a}}$ e $4^{\mathrm{a}}$ séries já apresentava respostas do nível 2. Mas quando se traça uma linha imaginária ao centro da figura, no sentido horizontal, percebe-se que existe uma relação maior do EJA com o nível 1B do que com o nível 1A. A $1^{\mathrm{a}}$ série, por sua vez, possui uma relação mais distante com o nível 1B e mais próxima com o nível $1 \mathrm{~A}$.

É possível concluir, portanto, que crianças da $1^{\mathrm{a}}$ série apresentavam mais respostas do nível primitivo do realismo nominal (1A), os adultos apresentavam-se no nível intermediário (1B) e as crianças da $2^{\mathrm{a}}$ e $4^{\mathrm{a}}$ séries já haviam superado o realismo nominal. Tais resultados sugerem que a superação do realismo nominal pode estar 


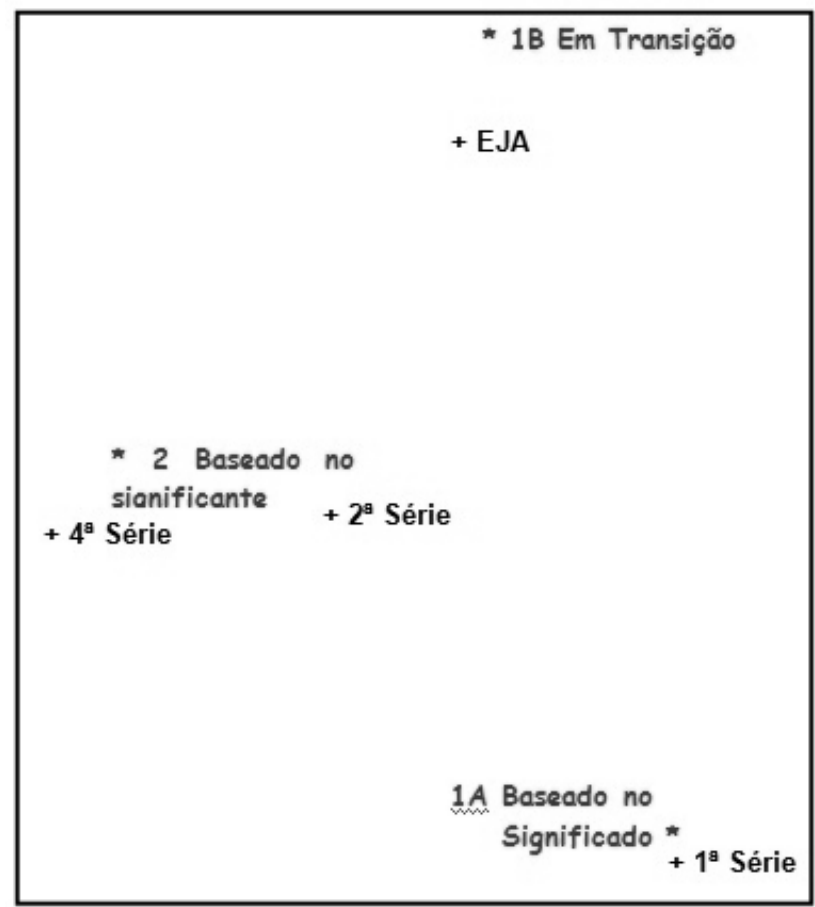

Figura 1. HOMALS. Relação de homogeneidade entre realismo nominal e série

mais relacionada ao grau de escolarização do que à idade cronológica. Entretanto, em comparação com as crianças, os adultos parecem avançar com mais facilidade na superação do realismo nominal. Foi possível perceber que as crianças apresentavam maior incidência de respostas do nível $1 \mathrm{~A}$ do que os adultos.

No que se refere à correlação entre leitura e realismo nominal, o teste Spearman's rho apresentou valor significativo $(r=0,593$ e $p<0,01)$. A Figura 2 demonstra a homogeneidade entre essas variáveis. Na parte inferior, observa-se que, em geral, os sujeitos que estão no nível $1 \mathrm{~A}$ do realismo nominal leem de forma não convencional ou segmentada, ou seja, tendem a apresentar os níveis mais baixos de decodificação. É possível observar do lado direito da figura dados que reiteram esta informação, já que demonstram, novamente, haver aproximação entre o nível $1 \mathrm{~A}$ do realismo nominal e a leitura não convencional ou segmentada.

Na parte superior, é possível identificar que os sujeitos que estão no nível 1B e 2 já conseguem ler com certa fluência. É importante evidenciar que existem nessas mesmas instâncias diferenças qualitativas de desempenho. Enquanto os sujeitos que apresentavam realismo nominal no nível 1B apresentavam leitura de palavras simples, os sujeitos do nível 2 já liam palavras complexas com fluência.

Conforme indicado, os sujeitos que estavam no nível $1 \mathrm{~A}$ do realismo nominal obtiveram menos sucesso na tarefa de leitura, lendo de forma não convencional ou segmentada. Diferentemente, os que se encontravam em fase de transição (1B) evoluíram para uma decodificação

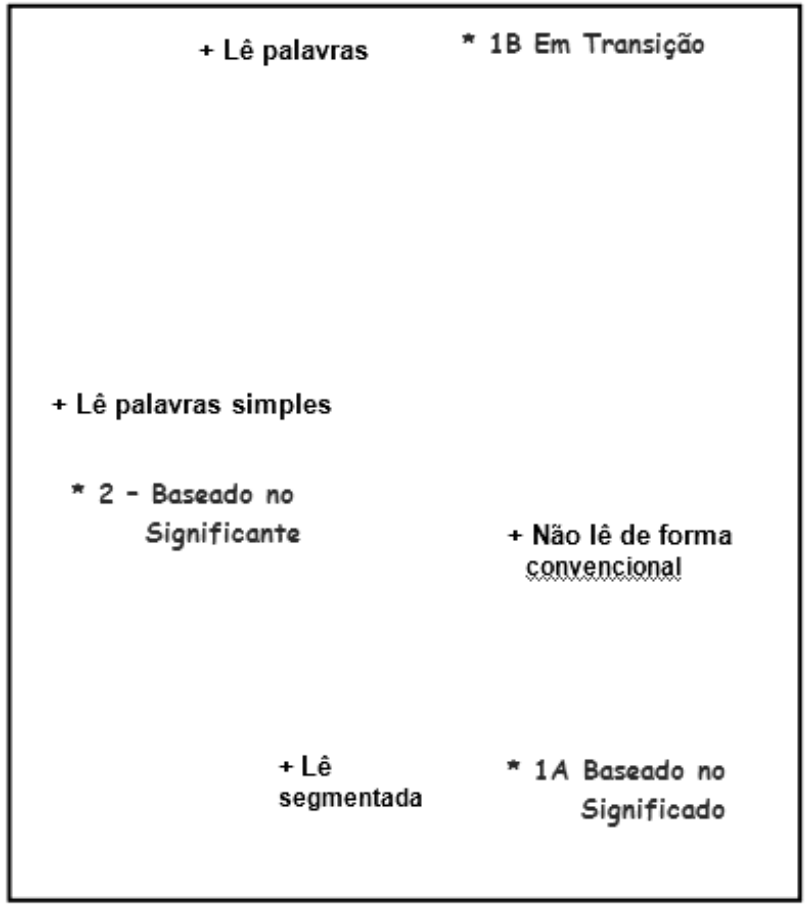

Figura 2. HOMALS. Relação de homogeneidade entre nível de leitura e realismo nominal

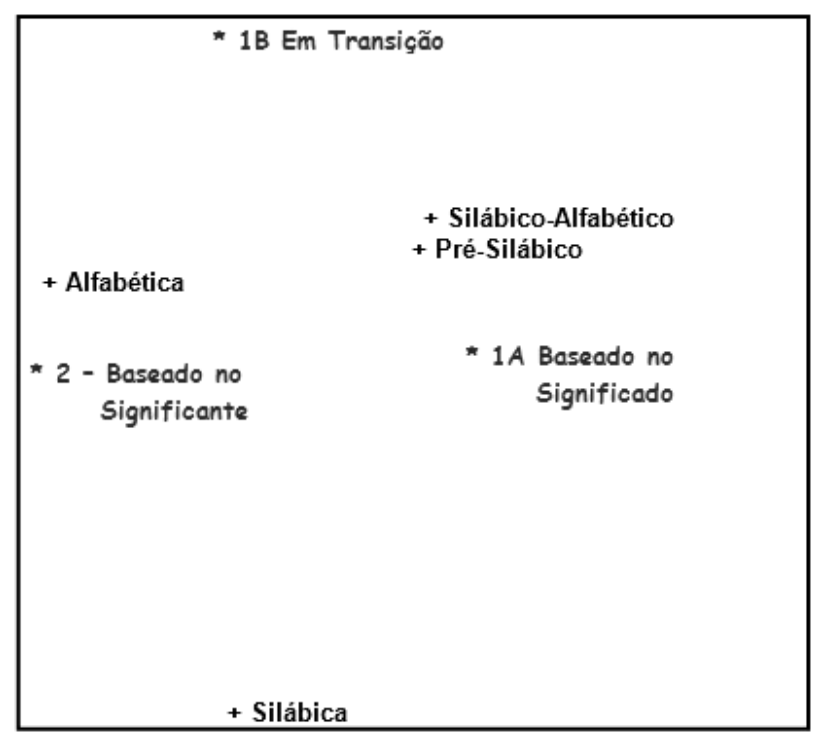

Figura 3. HOMALS. Relação de homogeneidade entre o nível de escrita e realismo nominal

mais sofisticada, enquanto os que já haviam superado o realismo nominal liam fluentemente. Tais resultados apontam que, de fato, o nível do realismo nominal está relacionado ao progresso na leitura. Se analisarmos as relações de homogeneidade entre o realismo nominal e a escrita, a partir da Figura 3, observa-se uma maior relação de proximidade entre o último nível do realismo nominal e o último do estágio da escrita.

Ao lado direito da Figura 3, é possível notar uma relação de proximidade do nível $1 \mathrm{~A}$ do realismo nominal com 
a hipótese pré-silábica, silábica e silábico-alfabética, embora esta relação tenha mais força nos níveis pré-silábico e silábico alfabético. Ao lado esquerdo da figura, é possível observar que a hipótese alfabética e o nível 2 do realismo nominal são as variáveis que expressam maior homogeneidade. Na parte superior, fica claro que o nível $1 \mathrm{~B}$, como dito anteriormente, apresenta relação com as várias hipóteses de escrita (exceto a silábica), ainda que não apresente uma relação intensa com nenhuma delas. Em resumo, os dados indicam que, em geral, aqueles que tinham menor consciência da palavra nos testes de realismo nominal apresentavam também menor possibilidade de dominar as habilidades da escrita.

Além das correlações e proximidades entre as variáveis mencionadas acima, os dados foram analisados a partir de testes de regressão logística com o objetivo de verificar em que proporção a variabilidade de uma variável dependente (realismo nominal ou consciência metalingüística) era previsível pelas variáveis independentes (atividades de leitura, escrita e cálculo). O motivo do uso da regressão logística decorre da natureza dicotômica da variável dependente.

Como já mencionado anteriormente, na mesma tarefa de realismo nominal foram extraídas duas diferentes va- riáveis: a variável intervalar de consciência metalinguística, utilizada nas regressões lineares; e uma variável ordinal referente aos níveis de realismo nominal, utilizada nas regressões múltiplas. Neste último caso, para efeito estatístico, foi necessário dicotomizar o nível de realismo nominal em duas modalidades: (a) Foi atribuído valor 1 para quem já havia superado o realismo nominal (Nível 2) e 0 para quem ainda apresentava o realismo nominal (Níveis $1 \mathrm{~A}$ e 1B). (b) Atribuiu-se 1 para os níveis $1 \mathrm{~B}$ e 2 do realismo nominal e 0 para o nível $1 \mathrm{~A}$.

$\mathrm{Na}$ Tabela 1, é apresentada a análise de regressão múltipla tipo passo a passo (Stepwise), considerando como variável dependente a medida de consciência metalinguística, ou seja, o número de acertos na tarefa de realismo nominal. Foram escolhidas como variáveis independentes as tarefas de matemática, categorização de sons, identificação e produção de rima, subtração de fonema, escrita (palavras e pseudopalavras), leitura (palavras e pseudopalavras) e o subteste de vocabulário do WISC.

Diante dessas variáveis independentes, foi possível observar duas variáveis que melhor predizem o desempenho na tarefa de consciência metalinguística: o ditado de pseudopalavras, explicando $47 \%$ da variância e, em seguida, matemática, explicando $5,9 \%$ da variância dos resultados na atividade.

Tabela 1

Análise de Regressão Múltipla do Tipo Passo a Passo Aplicada à Análise das Variáveis Preditoras da Consciência Metalinguística

\begin{tabular}{lccccccccr}
\hline Var. Independentes & $\mathrm{R}$ & $\mathrm{R}^{2}$ & $\begin{array}{c}\mathrm{r} \\
\text { (Pearson) }\end{array}$ & $\begin{array}{c}\text { Std. } \\
\text { Error }\end{array}$ & $\begin{array}{c}\mathrm{R}^{2} \\
\text { Change }\end{array}$ & $\begin{array}{c}\mathrm{F} \\
\text { Change }\end{array}$ & $\mathrm{gl}^{1}$ & $\mathrm{gl}^{2}$ & $\begin{array}{c}\text { Sig.F } \\
\text { Change }\end{array}$ \\
\hline 1. Ditado de pseudopalavras & 0,686 & 0,470 & 0,65 & 1,595 & 0,470 & 37,294 & 1 & 42 & 0,000 \\
2. Matemática & 0,727 & 0,529 & 0,63 & 1,522 & 0,059 & 5,101 & 1 & 41 & 0,029 \\
\hline
\end{tabular}

Nota. Variável Dependente: Consciência metalingüística (escore de acertos na tarefa de realismo nominal)/Variáveis Independentes: tarefas de matemática, categorização de sons, identificação e produção de rima, subtração de fonema, escrita (palavras e pseudopalavras), leitura (palavras e pseudopalavras), subteste de vocabulário do WISC.

Na Tabela 2, são apresentadas duas análises de regressão múltipla do tipo Passos Fixos. A primeira análise considerou como $1^{\circ}$ passo os escores nos subtestes WISC, $2^{\circ}$ passo escore de acertos na tarefa de matemática e $3^{\circ}$ passo Ditado de Não Palavras; e, como variável dependente, número de acertos na tarefa de consciência metalinguística de palavras reais através da tarefa de realismo nominal. A segunda análise é idêntica à primeira, com exceção da inversão do segundo passo com o terceiro.

A variável inteligência, dentro do limite das habilidades avaliadas pelos sub-testes do WISC, desempenha um importante efeito preditor na consciência metalinguística de palavras reais através da tarefa de realismo nominal, explicando $28,6 \%$ da variância. Após ter retirado o efeito da inteligência, o desempenho em matemática apresentou um efeito preditor significativo tanto quando era segundo passo (explicando 13,4\% da variância) como quan- do era terceiro passo (após ter controlado a habilidade de escrita de não palavras), explicando $6,1 \%$ da variância. Algo similar e com maior intensidade foi observado para a habilidade de escrita de não palavras. De fato, o desempenho nesta tarefa apresentou um efeito preditor significativo tanto quando era segundo passo (explicando 17,9\% da variância) como quando era terceiro passo (após ter controlado a habilidade de matemática), explicando $6,1 \%$ da variância.

Na Tabela 3, são apresentadas as regressões logísticas considerando como variável dependente o realismo nominal categorizado dicotomicamente. Enquanto na primeira análise o nível de realismo nominal foi dicotomizado considerando como valor 1 o Nível 2 (i.e., 1 = Nível 2 vs. 0 = Nível 1A e Nível 1B), na segunda análise, o nível de realismo nominal foi dicotomizado considerando como valor 1 o Nível 2 e o Nível 1B (i.e., 1 = Nível 2 
Tabela 2

Resultados da Regressão Múltipla do Tipo Passos Fixos Aplicada à Análise das Variáveis Preditoras da Consciência Metalinguística

\begin{tabular}{|c|c|c|c|c|c|c|c|c|c|}
\hline Var. Independentes & $\mathrm{R}$ & $\mathrm{R}^{2}$ & $\mathrm{R}^{2 \text { corrigido }}$ & $\begin{array}{l}\text { Std. } \\
\text { Error }\end{array}$ & $\begin{array}{c}\mathrm{R}^{2} \\
\text { Change }\end{array}$ & $\begin{array}{c}\mathrm{F} \\
\text { Change }\end{array}$ & $\mathrm{gl}^{1}$ & $\mathrm{gl}^{2}$ & $\begin{array}{l}\text { Sig.F } \\
\text { Change }\end{array}$ \\
\hline
\end{tabular}

\begin{tabular}{lccccccccc} 
1. WISC (3 subtestes) & 0,534 & 0,286 & 0,23 & 1,895 & 0,286 & 5,599 & 3 & 42 & 0,003 \\
\hline 2. Matemática & 0,648 & 0,420 & 0,36 & 1,729 & 0,134 & 9,453 & 1 & 41 & 0,004 \\
3. Ditado de pseudopalavras & 0,725 & 0,526 & 0,46 & 1,582 & 0,106 & 8,953 & 1 & 40 & 0,005 \\
\hline 2. Ditado de pseudopalavras & 0,682 & 0,465 & 0,41 & 1,660 & 0,179 & 13,708 & 1 & 41 & 0,001 \\
3. Matemática & 0,725 & 0,526 & 0,46 & 1,582 & 0,061 & 5,146 & 1 & 40 & 0,029
\end{tabular}

Tabela 3

Resultado da Regressão Logística Aplicada à Análise das Variáveis Preditoras do Realismo Nominal

\begin{tabular}{|c|c|c|c|c|c|c|c|}
\hline \multirow[t]{2}{*}{ Passos na Equação } & \multicolumn{2}{|c|}{ Aumento } & \multicolumn{4}{|c|}{ Modelo } & \multirow{2}{*}{$\begin{array}{c}\text { Nagel-kerke } \\
\mathrm{R}^{2}\end{array}$} \\
\hline & $\chi^{2}$ & gl & $\mathrm{P}$ & $\chi^{2}$ & gl & $\mathrm{P}$ & \\
\hline \multicolumn{8}{|c|}{ VD - 1 = Nível 2 e $0=$ Níveis $1 \mathrm{~A}$ e $1 \mathrm{~B}$} \\
\hline 1. Leitura de pseudopalavras & 18,408 & 1 & 0,001 & 18,408 & 1 & 0,001 & 0,507 \\
\hline \multicolumn{8}{|c|}{ VD - 1 = Níveis 2 e $1 \mathrm{~B}$ e 0 = Nível $1 \mathrm{~A}$} \\
\hline 1. Leitura de Palavras & 24,510 & 1 & 0,001 & 24,512 & 1 & 0,001 & 0,671 \\
\hline 2. Matemática & 10,061 & 1 & 0,002 & 34,573 & 2 & 0,001 & 0,845 \\
\hline
\end{tabular}

Nota. Variável Dependente: Nível do realismo nominal categorizado dicotomicamente/Variáveis independentes: tarefas de matemática, categorização de sons, identificação e produção de rima, subtração de fonema, escrita (palavra e pseudopalavras), leitura (palavra e pseudopalavras) e os sub-testes do WISC (Vocabulário, Ordem Direta e Ordem Inversa).

e Nível 1B vs. $0=$ Nível 1A). Em ambas as análises, a única variável que apresentou um efeito preditor bastante significativo foi leitura de palavras $\left[\chi^{2}=18,41\right.$, g.l. $=$ $1, p<0,001$ e $\chi^{2}=24,51$, g.1. $\left.=1, p<0,001\right]$. A tarefa de Matemática apresentou um efeito significativo somente quando a variável dependente considerava os níveis $2 \mathrm{e}$ 1B conjuntamente $\left[\chi^{2}=10,06\right.$, g.l. $\left.=1, p<0,002\right]$.

Entretanto, é importante ressaltar que o desempenho na tarefa de matemática não entrou na equação por uma diferença mínima, quando a variável dependente considerava separadamente o nível 2 em contraposição aos níveis $1 \mathrm{~A}$ e 1B. De fato, na estatística das variáveis, não na equação, a matemática se destaca com o valor de quiquadrado alto e marginalmente significativo $\left[\chi^{2}=3,799\right.$, g.l. $=1, p<0,051]$.

Os resultados dessas regressões logísticas, mencionados acima, assinalam tanto a importante contribuição de habilidades linguísticas (escrita de não palavras e leitura de palavras e não palavras) como também das habilidades matemáticas na superação do realismo nominal.

\section{Discussão}

Os dados avaliados nesta investigação reiteram a presença do realismo nominal tanto em adultos quanto em crianças nas séries inicias de escolarização, como já havia sido demonstrado em estudos anteriores (Bezerra, 1981; Carraher \& Rego, 1981, 1984; Maluf \& Barrera, 1997; Monteiro, 1981, entre outros). Os resultados também indicam que, em geral, adultos parecem superar mais rápido o realismo nominal do que crianças, tendo em vista o pequeno número de adultos que apresentaram o nível mais primitivo do realismo nominal.

Confirma-se que a superação do realismo nominal está associada a um melhor desempenho nas atividades de leitura. Embora no estudo de Carraher e Rego (1984) a correlação entre realismo nominal e escrita tenha mostrado-se pouco evidente, os dados deste estudo indicaram que com a evolução do domínio da escrita, o realismo nominal tende a ser superado.

Outro dado importante a ser discutido é que os sujeitos que já haviam superado o realismo nominal escreviam de forma alfabética; porém, aqueles que ainda se baseavam fortemente no significado encontravam-se nas hipóteses pré-silábica e silábica alfabética. Na literatura relacionada à psicogênese da escrita, o realismo nominal é relacionado apenas às crianças que escrevem conforme a hipótese pré-silábica (Aquino, 2007; Coutinho, 2005; Mercado, 2000; Rego, 1992, entre outros). É possível que tal resultado esteja relacio- 
nado a certas hipóteses e estratégias mais elaboradas para compreender a dissociação entre signo/objeto, cuja categorização utilizada para avaliar níveis de realismo nominal não permitiu visualizar. Tais estratégias serão discutidas em estudo posterior.

A consciência metalinguística realmente parece estar correlacionada ao realismo nominal. $\mathrm{O}$ ditado de não palavras mostrou-se um bom preditor de consciência metalinguistica, assim como a leitura mostrou-se preditora do realismo nominal. De fato, o exercício dessas duas tarefas exige do sujeito uma maior necessidade em focar a palavra e refletir sobre a mesma. Assim, é possível explicar que sujeitos que apresentam melhor desempenho no ditado de não palavras e leitura, previsivelmente, apresentam consciência metalinguística desenvolvida e realismo nominal superado.

Dentre todos os resultados, o mais relevante foi o que apontou para a correlação do realismo nominal com a matemática. Esta variável, em determinadas manipulações estatísticas dos dados, também mostrou predizer a consciência metalinguística e realismo nominal. Talvez este resultado possa trazer a tona uma reflexão sobre a natureza do realismo nominal.

Embora muito tenha se falado sobre a interferência do realismo nominal na leitura e escrita (Bezerra, 1981; Carraher \& Rego, 1981, 1984; Maluf \& Barrera, 1997; Monteiro, 1981), é possível que o cerne da questão não esteja relacionado especificamente ao realismo nominal, e sim, a um aspecto mais amplo do desenvolvimento cognitivo: a dificuldade em compreender arbitrariedades e desligar-se do perceptual concreto.

A linguagem matemática também é um sistema arbitrário. Dificilmente a linguagem traz em si características explicitas e concretas de um objeto, como no caso da linguagem dos numerais em Munducuru - língua indígena na qual os numerais são usualmente compridos, tendo tantas sílabas quanto as quantidades correspondentes (Butterworth \& Reeve, 2008). Hughes (1986) mostrou que símbolos abstratos como "+" e "=" e linguagem abstrata como " $2+3=5$ " fazem pouquíssimo sentido para as crianças. Pesquisas apontam que assim como as crianças correlacionam o nome a um atributo físico daquilo ao qual se referem, elas também apresentam ideias similares para a escrita arbitrária dos números (Brizuela, 1998; Lerner \& Sadowsky, 1996). Tal dificuldade com a natureza arbitrária dos sistemas de notação poderia justificar o baixo desempenho dos participantes na atividade de matemática.

Diante do que já foi exposto, conclui-se que os dados analisados neste estudo confirmam a hipótese de que adultos e crianças apresentam realismo nominal, ainda que em níveis diferentes. Entretanto, em ambos os casos, o realismo nominal parece influenciar não só na leitura e escrita, mas também nas atividades matemáticas. Tal fato, aparentemente, indica que o realismo nominal influencia na compreensão da natureza arbitrária do sistema notacional alfabético e numérico.
É preciso que outras pesquisas sobre o tema sejam realizadas a fim de esclarecer melhor o fenômeno em questão. Algumas investigações envolvendo realismo nominal e matemática já estão sendo realizadas para posterior esclarecimento desta correlação.

No entanto, se comprovarmos que existe correlação entre o nível de realismo nominal lógico e o desempenho nas atividades de matemática, será possível desmistificar o conceito de que o realismo nominal é um obstáculo exclusivo à leitura. Será admissível considerá-lo como um indicativo do nível de desenvolvimento cognitivo da criança que aponta para dificuldades específicas na aquisição dos sistemas notacionais. Confirmando-se esta idéia, iniciam-se novas possibilidades de investigações sobre o tema, bem como novas contribuições para a prática pedagógica e psicopedagógica que facilitem a apropriação das notações alfabéticas e numéricas.

\section{Referências}

Andreazza-Balestrin, C., Cielo, C. A., \& Lazzarotto, C. (2008). Relação entre desempenho em consciência fonológica e a variável sexo: Um estudo com crianças pré-escolares. Revista da Sociedade Brasileira de Fonoaudiologia, 13(2), 154-160.

Aquino, S. B. (2007). O trabalho com consciência fonológica na educação infantil e o processo de apropriação da escrita pelas crianças. Dissertação de Mestrado não-publicada, Universidade Federal de Pernambuco, Recife, PE.

Ball, S. E., \& Simpson, R. A. (1977). Shifts from nominal realism in grade school children as a function of participating in a naming task. The Journal of Psychology, 96, 217-221.

Bezerra, W. (1981). Consciência metalingüística em adultos analfabetos. Dissertação de Mestrado não-publicada, Universidade Federal de Pernambuco, Recife, PE.

Brizuela, B. (1998). Invenções e convenções: Uma história sobre números maiúsculos. In A. Schilemann \& D. W. Carraher (Eds.), A compreensão de conceitos aritméticos: Ensino e pesquisa: Perspectivas em Educação Matemática (pp. 3952). Campinas, SP: Papirus.

Butterworth, B., \& Reeve, R. (2008). Verbal counting and spatial strategies in numerical tasks: Evidence from Indigenous Australia. Philosophical Psychology, 21(4), 443-457.

Camargo, H. S. (2007). A rima como estratégia cognitiva no letramento de jovens e adultos. Dissertação de Mestrado nãopublicada, Universidade Federal do Paraná, Curitiba, PR.

Carraher, T. N., \& Rego, L. L. B. (1981). O realismo nominal como obstáculo na aprendizagem da leitura. Cadernos de Pesquisa, 39, 3-10.

Carraher, T. N., \& Rego, L. L. B. (1984). Desenvolvimento cognitivo e alfabetização. Revista Brasileira de Estudos Pedagógicos, 65(149), 38-55.

Church, J. (1961). Language and the discovery of reality. New York: Vintage Books.

Coutinho, M. L. (2005). Psicogênese da língua escrita: O que é? Como intervir em cada uma das hipóteses? Uma conversa entre professores. In A. G. Morais, E. B. C. Albuquerque, \& T. F. Leal (Eds.), Alfabetização: Apropriação do sistema alfabético (pp. 47-70). Belo Horizonte, MG: Autentica. 
De Leeuw, J., \& Van Rijckevorsel, J. (1980). HOMALS and PRINCALS: Some generalizations of principal components analysis. In E. Diday (Ed.), Data analysis and informatics (pp. 231-242). Amsterdam, Netherlands: North-Holland.

Ferreiro, E., \& Teberosky, A. (1991). A psicogênese da lingua escrita (4. ed). Porto Alegre, RS: Artes Médicas.

Furth, H. G. (1969). Piaget and knowledge: Theoretical foundation. Englewoood Cliffs, NJ: Prentice Hal.

Gerschitz, E., \& Glick, J. (1981). The consequences of nominal realism for symbolic mediation. The Journal of Genetic Psychology, 139, 173-183.

Gindri, G., Keske-Soares, M., \& Mota, H. B. (2007). Memória de trabalho, consciência fonológica e hipótese de escrita. Pró-Fono: Revista de Atualização Científica, 19(3), 313-322.

Guttman, L. (1941). The quantification of a class of attributes: A theory and method of scale construction. In P. Horst (Ed.), The prediction of personal adjustment (pp. 319-348). New York: Social Science Research Council.

Hughes, M. (1986). Children and number. New York: SpringerVerlag.

Lerner, D., \& Sadowsky, P. (1996). O sistema de numeração: Um problema didático. In C. Parra \& I. Saiz (Eds.), Didática da Matemática: Reflexões psicopedagógicas (pp. 73-155). Porto Alegre, RS: Artes Médicas.

Lima, R. (2002). O efeito preditor das habilidades fonológicas sobre a leitura e a escrita. Dissertação de Mestrado nãopublicada, Universidade Federal de Pernambuco, Recife, PE.

Maia, A. C., \& Fonseca, M. L. (2002). Quociente de inteligência e aquisição de leitura: Um estudo correlacional. Psicologia: Reflexão e Crítica, 15(2), 261-270.

Maluf, M. R., \& Barrera, S. D. (1997). Consciência fonológica e linguagem escrita em pré-escolares. Psicologia: Reflexão e Crítica, 10(1), 125-145.

Markman, E. M. (1976). Children's difficulty with wordreference differentiation. Child Development, 47(3), 742-749.

Melo, L. A. (2004). De Piaget a Feuerstein: Um estudo do letramento e da mediação na educação especial. Dissertação de Mestrado não-publicada, Universidade Católica de Pernambuco, Recife, PE.

Mercado, E. (2000). Crianças com Síndrome de Down e a possível construção da base alfabética. Revista do CEDU - UFAL, 8(12), 30-47.

Miranda, M. I. (2008). Epistemologia genética, alfabetização e letramento. Educação e Filosofia, 22(44), 141-158.

Monteiro, U. N. (1981). Consciência metalingüística: Uma análise em adultos analfabetos. Dissertação de Mestrado nãopublicada, Universidade Federal de Pernambuco, Recife, PE.

Moreira, C. M. (2006). Níveis lingüísticos na leitura inicial: Uma aquisição gradativa? Revista Inventário, 5, 1-19 Retrieved August 15, 2009, from http://www.inventario.ufba.br/05/ pdf/cmoreira.pdf

Nunes, T., \& Moreno, C. (1998). Is hearing impairment a cause of difficulties in learning mathematics? In C. Donlan (Ed.), The development of mathematical skills (pp. 227-254). Hove, UK: Psychology Press.

Papandropoulou, I., \& Sinclair, H. (1974). What's in a word? Experimental study of children's ideas on grammar. Human Development, 17(4), 241-258.

Piaget, J. (1962). A representação do mundo na criança. Rio de Janeiro, RJ: Record.

Pulaski, M. A. S. (1971). Understanding Piaget: An introduction to children's cognitive development. New York: Harper \& Row.
Rego, L. B. (1992). Descobrindo a língua escrita antes de aprender a ler: Algumas implicações pedagógicas. In M. A. Kato (Ed.), A concepção da escrita pela criança (pp. 105-134). Campinas, SP: Pontes.

Roazzi, A., \& Carvalho, M. R. (1995). O desenvolvimento de habilidades de segmentação lexical e a aquisição da leitura. Revista Brasileira de Estudos Pedagógicos, 76(184), 477548.

Salvari, L. (2004). A relação entre família e problemas de aprendizagem: O que pensam psicólogos e pedagogos. Dissertação de Mestrado não-publicada, Universidade Católica de Pernambuco, Recife, PE.

Simões, V. L. (2000). Histórias infantis e aquisição de escrita. São Paulo em Perspectiva, 14(1), 22-28.

Soares, M. (2004). Letramento e alfabetização: As muitas facetas. Revista Brasileira de Educação, 25, 5-17.

Tenenhaus, M., \& Young, F. W. (1985). An analysis and synthesis of multiple correspondence analysis, optimal scaling, dual scaling, homogeneity analysis and other methods for quantifying categorial multivariate data. Psychometrika, 50, 91-119.

Werner, H. (1948). Comparative psychology of mental development. New York: University Press.

Williams, R. (1990). God-concept socialization: Some explanations from Piaget. Religious Education, 85(2), 311-315.
Recebido: 23/09/2009 $1^{a}$ revisão: 04/02/2010 $2^{a}$ revisão: $15 / 03 / 2010$ Aceite final: $18 / 03 / 2010$ 